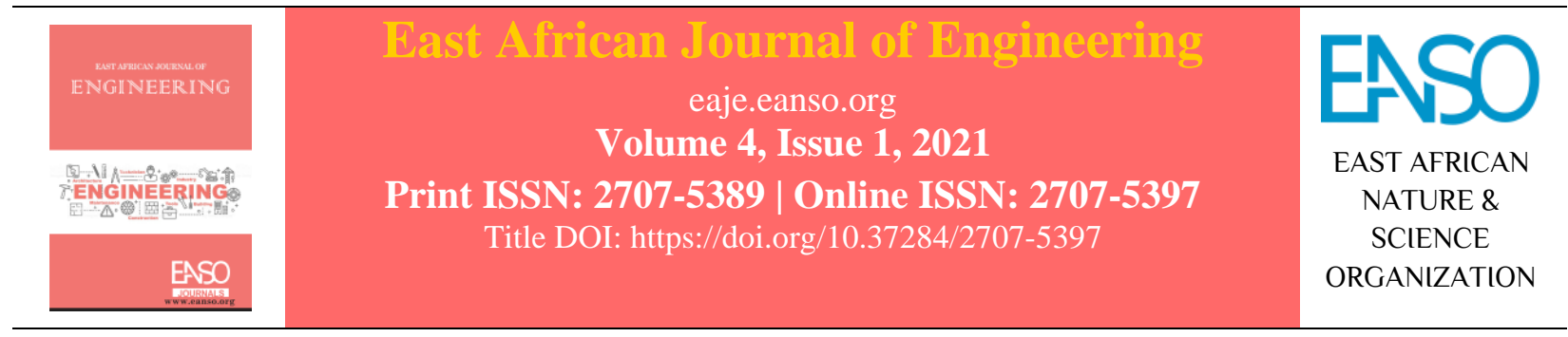

Original Article

\title{
Statistical Model for Predicting Salinity of Water at Doho 1 Irrigation Scheme in Busia.
}

\author{
Christine Keneema ${ }^{l}$, Semwogerere Twaibu, $\mathrm{PhD}^{l *}$, Kamalha Edwin ${ }^{l}$, Alio Deborah ${ }^{l} \&$ Kawuma $_{\text {Carol }}{ }^{1}$ \\ ${ }^{1}$ Busitema University, P. O. Box 236, Tororo, Uganda. \\ * Author for Correspondence ORCID ID: https://orcid.org/0000-0002-7276-844; Email: tsemwogerere@eng.busitema.ac.ug.
}

Article DOI: https://doi.org/10.37284/eaje.4.1.504

\begin{abstract}
Publication Date: ABSTRACT
13 December 2021 The concentration of salts in water or salt affects crop yields to a good extent. Irrigation salinity can be controlled by various methods including

Keywords: modelling. Therefore, this study aimed at designing a model for predicting the salinity of the water at the Doho Irrigation Scheme in Butaleja district,

Chemical, eastern Uganda for better rice growing. This study used the different water Electrical Conductivity,

Rice Growing, Salinity,

Statistical Model. chemical parameters from the different sites of the scheme, where water samples were collected and measured in the laboratory. A multivariate regression method was used to model water salinity through the Electrical Conductivity as the dependent variable and other water chemical parameters like potassium $(\mathrm{K})$, Sodium $(\mathrm{Na}), \mathrm{pH}$ and Calcium $(\mathrm{Ca})$ were used as independent variables. A non-linear statistical model was derived from the chemical results of the irrigation scheme, presented and validated by applying it on the water samples that were not used during the design of the model. The model measured salinity levels and can be used to determine which water chemical levels are good for rice growing in Doho and other similar situations. Hence, the model can be used to improve food quality and quantity as required in the food production goal.
\end{abstract}

\section{APA CITATION}

Keneema, C., Twaibu, S., Edwin K., Deborah A., \& Carol, K. (2021). Statistical Model for Predicting Salinity of Water at Doho 1 Irrigation Scheme in Busia. East African Journal of Engineering, 4(1), 39-47. https://doi.org/10.37284/eaje.4.1.504

\section{CHICAGO CITATION}

Keneema, Christine, Semwogerere Twaibu, Kamalha Edwin, Alio Deborah \& Kawuma Carol. 2021. "Statistical Model for Predicting Salinity of Water at Doho 1 Irrigation Scheme in Busia”. East African Journal of Engineering 4 (1), $39-47$. https://doi.org/10.37284/eaje.4.1.504.

\section{HARVARD CITATION}

Keneema, C., Twaibu, S., Edwin K., Deborah A., \& Carol, K. (2021) "Statistical Model for Predicting Salinity of Water at Doho 1 Irrigation Scheme in Busia”, East African Journal of Engineering, 4(1), pp. 39-47. doi: 10.37284/eaje.4.1.504.

\section{IEEE CITATION}

39 | This work is licensed under a Creative Commons Attribution 4.0 International License. 
C., Keneema., S. Twaibu., K. Edwin., A. Deborah., \& K. Carol., "Statistical Model for Predicting Salinity of Water at Doho 1 Irrigation Scheme in Busia," EAJE, vol. 4, no. 1, pp. 39-47, Nov. 2021.

\section{MLA CITATION}

Keneema, Christine, Semwogerere Twaibu, Kamalha Edwin, Alio Deborah \& Kawuma Carol. "Statistical Model for Predicting Salinity of Water at Doho 1 Irrigation Scheme in Busia." East African Journal of Engineering, Vol. 4, no. 1, Nov. 2021, pp. 3947, doi:10.37284/eaje.4.1.504.

\section{INTRODUCTION}

The agriculture sector in Uganda contributes $40 \%$ of the total goods exported, thereby providing a high potential for income generation and foreign exchange. It is important to note that for the agricultural sector to yield satisfactorily, irrigation serves as one of the basic factors that are considered in addition to fertilizers and other ingredients with the need to balance the water and soil parameters. These parameters include Electrical Conductivity, PH, Sodium, Calcium, Magnesium and Potassium, among others. These parameters have been reported by previous authors like Chemura et al. (2014), Ajala et al. (2016), Dobermann and Fairhurst (2000) and Bonansea et al. (2015) to be essential for proper crop growth and are also needed for the physiology of crops.

The agricultural sector is facing challenges of low productivity noted over the past years due to unreliable rainfall conditions (Ajala et al., 2016). In a bid to improve this fundamental sector of the economy, the government of Uganda through the Ministry of Water and Environment put up mitigation measures through the construction of a number of irrigation schemes like the Agoro Irrigation Scheme in Lamwo district and Doho Irrigation Scheme in Butaleja district, among others. This was done in addition to rehabilitating some of the long-serving irrigation schemes like the Doho1 irrigation scheme in the Butaleja district. Rehabilitation usually involves the usage of heavy machinery that often times have an impact on the chemical content of water which is disastrous in case the chemical content goes way beyond the desirable rates for proper growth of rice (Bai et al., 2017; Cocozza et al., 2013).
The study done by Ajala et al. (2016) noted that the major problems facing irrigated land are salinity and sodicity as these cause poor water and nutrient uptake by a plant which is usually wrongly interpreted as lack of adequate irrigation or fertilization. Also, saline conditions reduce the osmotic ability of crops which inhibits their water absorption abilities leading to low yields (Bendra $e t$ al., 2012; Bauder et al., 2011; WSRS, 2007).

Oil also contains hydrocarbons whose presence directly affects water quality parameters like BOD, $\mathrm{PH}$, Turbidity, Electro conductivity leading to salinity and sodicity (Uhegbu et al., 2011; Rahman et al., 2012). A statistical model can ably help in the tuning of the right quantity combination in the irrigation process and can be used for extrapolation.

Therefore, this study aimed at designing a model for measuring the salinity of the water at the Doho 1 irrigation scheme with the aim of determining the levels to or from the required threshold. The research studied the chemical components of water at the irrigation scheme in a bid to manage chemical water components, thus aiming at increased crops yields through control of the water parameters at the irrigation scheme. The research designed a statistical model for measuring water salinity at Doho 1 irrigation scheme.

\section{METHODOLOGY}

\section{Study Area}

The study was carried out in Doho 1 Irrigation Scheme situated in Mazimasa and Kachonga subcounties of Bunyole County, Butaleja District, Eastern Uganda. It is located $49 \mathrm{~km}$ from Tororo town and $25 \mathrm{~km}$ away from Mbale and about 260 $\mathrm{km}$ from Kampala, the capital city of Uganda. The

40 This work is licensed under a Creative Commons Attribution 4.0 International License. 
Rice Scheme is the second largest in Uganda covering about 2500 hectares of land as indicated in Figure 1 .

\section{Figure 1: Map Extracts Showing the Study Area}

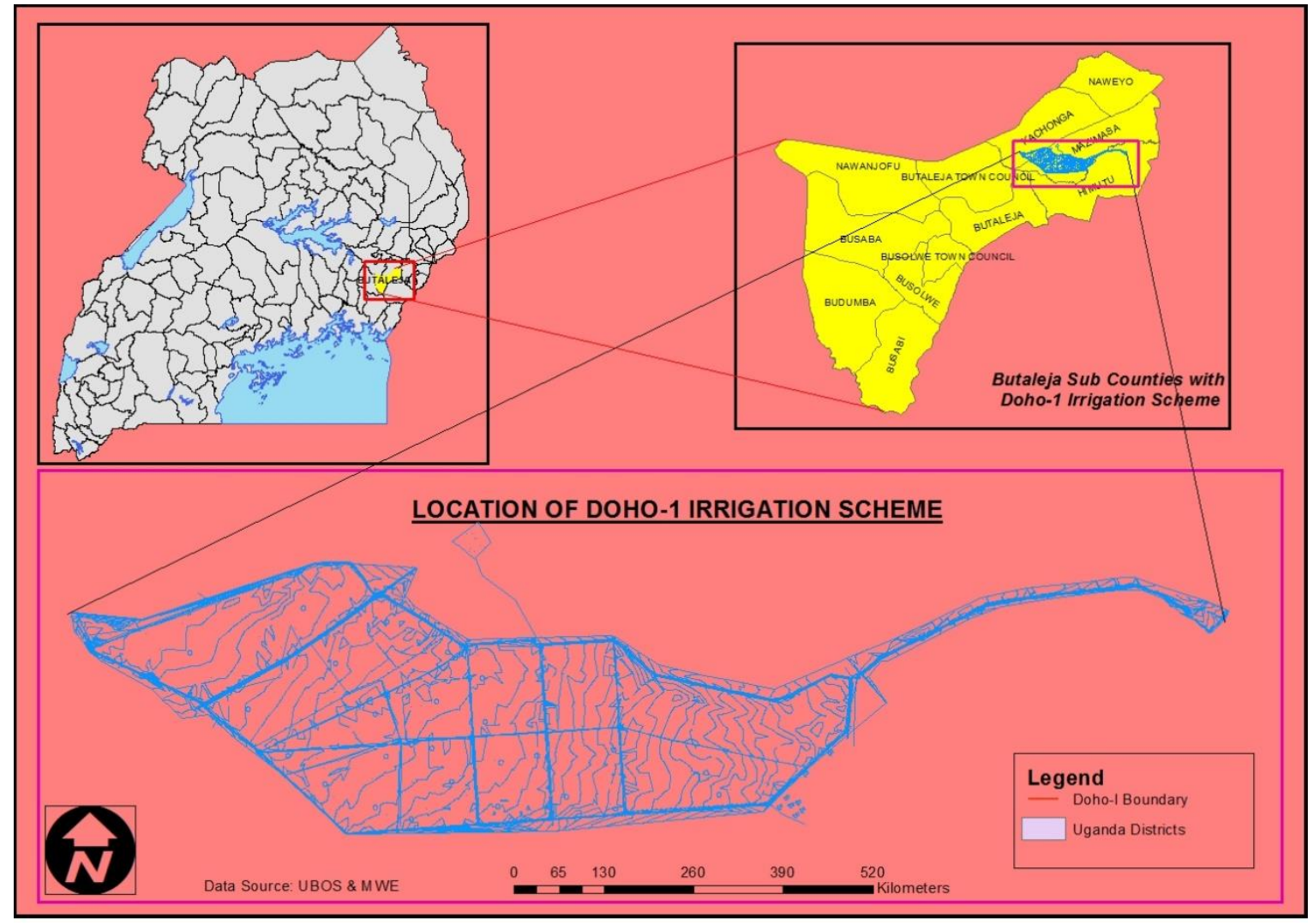

The scheme was purposively selected because of the recent rehabilitations it has gone through in an effort to make it more efficient for rice growing.

\section{Sampling Procedures, Data Collection and Analysis}

A completely randomized study design was employed to guide water sampling in the Doho irrigation scheme. Six water samples used for irrigation were collected from the different blocks and the seventh sample (control) from the main river (Manafwa) that supplies the scheme with water. These water samples were packaged in clean bottles and taken to the laboratory for testing and water chemical/parameters content was measured. The data was analyzed using stat V13 and presented as averages and percentages to show the significance of each chemical component on salinity.

\section{Model Formulation}

A statistical model was formulated following analysis of the data whereby those properties that were more significant to salinity levels were used in the model formulation. A simple linear regression model and the relationship between the observed and estimated value of dependent variable were specified as;

41 This work is licensed under a Creative Commons Attribution 4.0 International License. 
$Y=a+b x$

$Y i=a+b X+\varepsilon i$

where $Y$ is the measured value, $Y i$ is the calculated value, $\boldsymbol{a}$ is the constant, $\boldsymbol{b}$ is the slope, $\mathrm{i}$ is the error associated with an estimate of $Y i$, and the value of $X=x i$ is the given value of the independent variable as indicated in Equations (1) and (2). The constants a and $\boldsymbol{b}$ are estimated by the ordinary least squares technique. If $i=0$, the calculated value $(Y)$ is equal to the measured value $(Y i)$.

The Multiple Linear Regression (MLR) is very similar to simple linear regression, but the difference in MLR is that the dependent variable is a function for more than one independent variable. This was used to MIR determine the variation of the model and the relative contribution of the EC. The embedded assumptions to this modelling were all taken care of as observed from the parameters identified for the model. MLR was specified using Equation (3),
$Y i=a+b 1 X 1+b 2 X 2+\cdots b n X n+\varepsilon i$

where $Y i, a$ and $E i$ have already been described, $b 1$, $b 2$..., $b n$ are the partial regression (slope) parameter for $X 1, X 2 \ldots, X n$. The main purpose of using MLR was used to find the linear relationship between dependent and independent variables and to obtain a linear model using regression coefficients as well as to calculate the dependent variable. For the best-calculated value of the dependent variable, $\varepsilon i$ could be specified as given in Equation (4):

$\sum_{i=1}^{n}(\varepsilon i) 2=\sum_{i=1}^{n}(Y i-a+b i X 1+b 1 X 2+\cdots+$ bnXn)2

\section{RESULTS AND DISCUSSION}

\section{Chemical Properties}

The chemical properties of water were each measured at the different study sites and the average results of hydrogen potential, electrical conductivity, Turbidity, total dissolved solids, Calcium, Magnesium, potassium and Sodium were recorded as observed in Table 1 .

Table 1: Chemical Properties of the Irrigation Scheme Water

\begin{tabular}{lllllllllll}
\hline ID & pH & $\begin{array}{l}\text { EC } \\
\mathbf{u S} / \mathbf{c m}\end{array}$ & $\begin{array}{l}\text { Turbidity } \\
\text { NTU }\end{array}$ & $\begin{array}{l}\text { TSS } \\
\mathbf{m g} / \mathbf{L}\end{array}$ & $\begin{array}{l}\text { Total } \\
\text { Hardness } \\
\mathbf{m g} / \mathbf{L}\end{array}$ & $\begin{array}{l}\text { Ca } \\
\text { Hardness } \\
\mathbf{m g} / \mathbf{L}\end{array}$ & $\begin{array}{l}\text { Ca } \\
\mathbf{m g} / \mathbf{L}\end{array}$ & $\begin{array}{l}\text { Mg } \\
\mathbf{m g} / \mathbf{L}\end{array}$ & $\begin{array}{l}\mathbf{K} \\
\mathbf{m g} / \mathbf{L}\end{array}$ & $\begin{array}{l}\mathbf{N a} \\
\mathbf{m g} / \mathbf{L}\end{array}$ \\
\hline Average & 7 & 286.56 & 565.74 & 38.00 & 123.67 & 68.22 & 27.29 & 13.31 & 5.93 & 5.93 \\
Max & 7.5 & 395 & 1262 & 61 & 185 & 91 & 36.4 & 25.44 & 8.60 & 8.6 \\
Min & 6.3 & 196 & 44.1 & 13.4 & 87 & 48 & 19.2 & 8.64 & 4.10 & 4.1 \\
StdDev & 0.34 & 76.60 & 477.04 & 16.99 & 30.09 & 11.61 & 4.64 & 5.25 & 0.43 & 1.70 \\
\hline
\end{tabular}

pH

The Food and Agricultural Organization (FAO) guidelines recommend a $\mathrm{pH}$ range for irrigation water of 6.5 to 8.5 (Salman et al., 2019) for proper rice yields. In this research, the $\mathrm{pH}$ was within the recommended normal range from 6.66 and 7.34 and therefore did not require adjustment. This was also supported by Bwambale and others (Bwambale et $a l ., 2019)$ in their study about the Water Allocation Model.

\section{Salinity}

Electrical Conductivity (EC) is the measure of salinity. FAO guidelines recommend an EC of up to $700 \mu \mathrm{S} / \mathrm{cm}$ (Salman et al., 2019). All the water samples tested had salinity within the normal range 
averaging to $286.58 \pm 76.60 \mu \mathrm{S} / \mathrm{cm}$. This means that rice can still grow well in the available conditions.

\section{Total Suspended Solids}

The danger with suspended solids is that they cause clogging of the water emitting system. This is in the piped irrigation system, but in Doho1, where this study was carried out which uses a flooding system in the rice fields, total suspended solids may not be a serious problem unless a lot of woody and leafy materials are deposited causing blockage of the water supply canals.

\section{Total Hardness}

This is an indicator of the amount of calcium and magnesium in water. Water contains salts of calcium and magnesium which lead to hardness, although other elements like iron, manganese, aluminium and zinc can contribute to the hardness. Both calcium and magnesium are essential elements for crop growth. A total hardness of up to $500 \mathrm{mg} / \mathrm{L}$ is permissible. Total hardness for all the water samples that were tested was within the normal range which averaged $123.69 \pm 30.09 \mathrm{mg} / \mathrm{L}$.

\section{Calcium Hardness}

Since calcium is a crop nutrient, it is desirable that irrigation water contains this element. However, its salts could be in concentrations that lead to hardness. The permissible calcium hardness in

\section{Figure 2: Relationship between EC and pH}

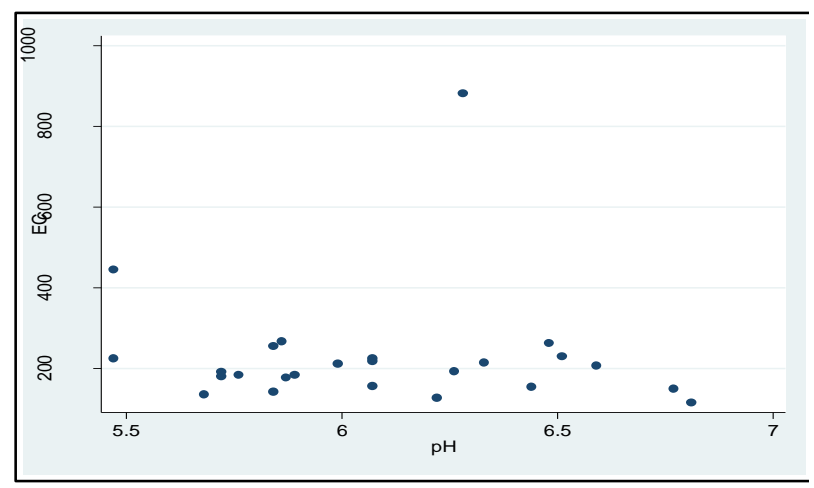

irrigation water ranges from 40 to $100 \mathrm{mg} / \mathrm{L}$. Luckily, calcium hardness for all the water samples tested under this study was within the normal range.

\section{Calcium, Magnesium, Potassium and Sodium Content}

Normal ranges of calcium, magnesium, potassium and sodium are: 0-20 me/L, 0-5 me/L, 0-2 me/L and 0-40 me/L respectively. For all the parameters in all the water samples, the levels were within the normal ranges.

\section{Statistical Model}

This research uses a multilinear regression method where a dependent variable is assumed to be a linear function of more than one independent variable. Water salinity is measured using Electrical Conductivity in $\mathrm{dSm}^{-1}$.

Total dissolved salts and EC are good parameters for measuring water quality since they give the salt composition of the soil and water in question (AlMukhtar \& Al-Yaseen, 2019; Rahman et al., 2012) argue that TDA and EC are directly associated with the concentration of salt in water and hence high values of these parameters cause low water quality indices. We do correlation scatter plots to determine the relationship between EC, the dependent variable and all independent variables as presented in Figures 2-5.

\section{Figure 3: Relationship between EC and K}

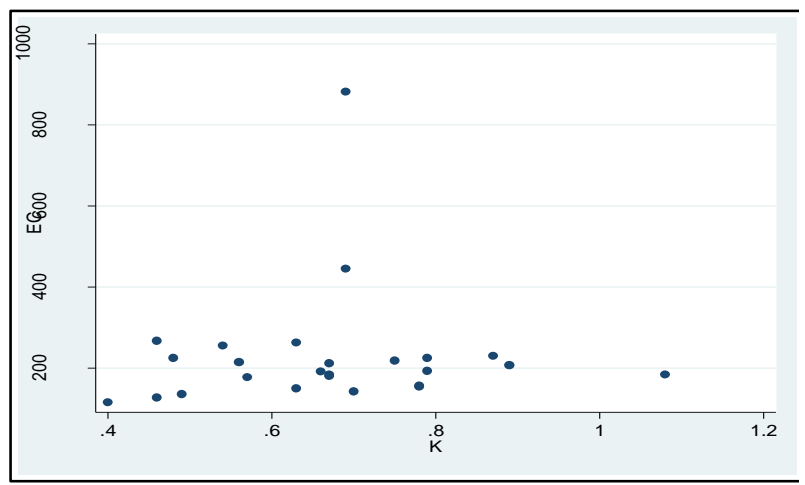

43 This work is licensed under a Creative Commons Attribution 4.0 International License. 
Figure 4: Relationship between EC and Na

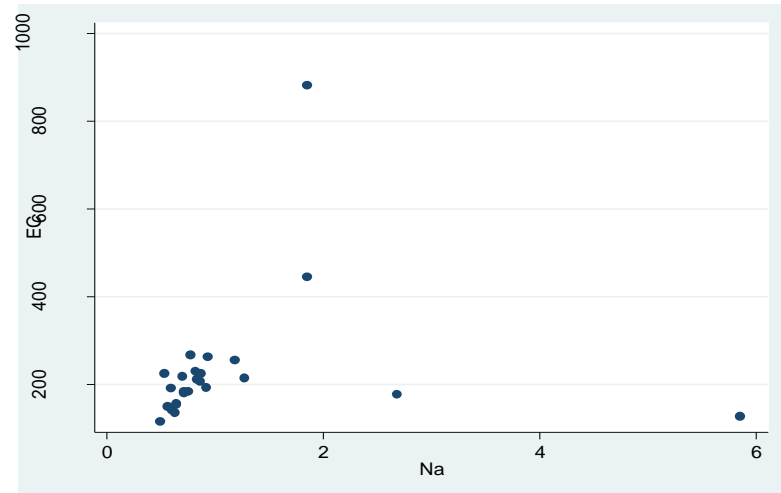

Testing for correlation using the collinearity matrix, the following graphs were the result; the process is aimed at identifying which independent variable has more impact on the dependent variable. We intend
Figure 5: Relationship between EC and Ca

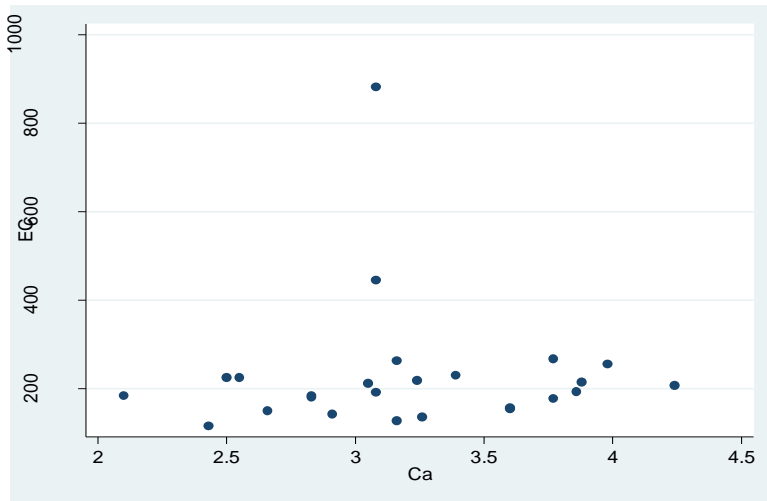

to measure whether an increase and independent variable results in an equal increase or reduction in the dependent variable.

Figure 6: Correlation Matrix for some Chemical Properties

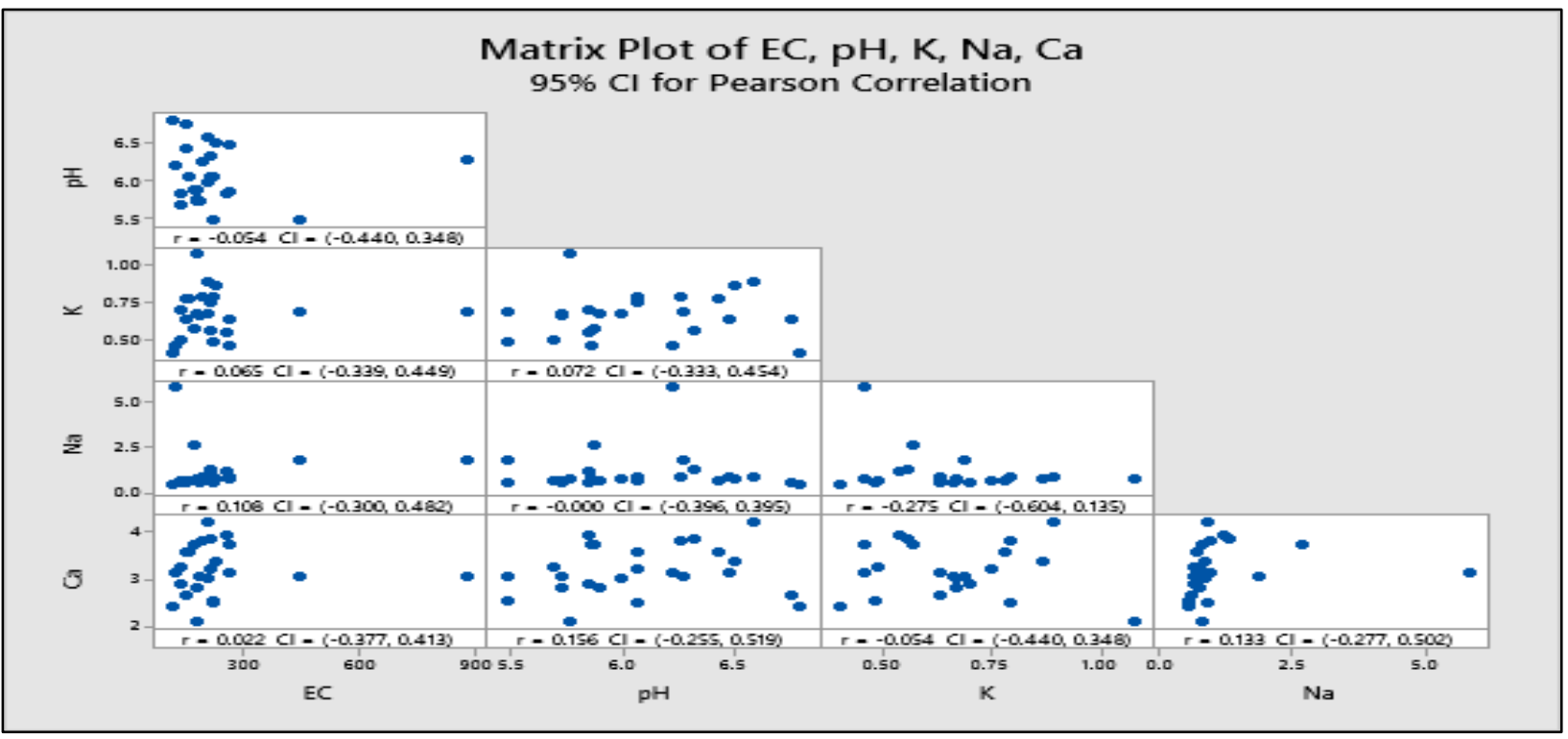

Table 2: Correlation Values relating Figure 6

\begin{tabular}{llllll}
\hline & $\mathbf{E C}$ & $\mathbf{p H}$ & $\mathbf{K}$ & $\mathbf{N a}$ & $\mathbf{C a}$ \\
\hline $\mathbf{E C}$ & 1.0000 & & & & \\
$\mathbf{p H}$ & -0.054 & 1.0000 & & & \\
$\mathbf{K}$ & 0.065 & 0.072 & 1.0000 & & \\
$\mathbf{N a}$ & 0.108 & -0.000 & -0.275 & 1.0000 & 1.0000 \\
$\mathbf{C a}$ & 0.022 & 0.156 & -0.054 & 0.133 & \\
\hline
\end{tabular}

44 | This work is licensed under a Creative Commons Attribution 4.0 International License. 
We then check multicollinearity so as to avoid variables with the same or related coefficients effect on the dependent variable using ANOVA as indicated in Table 3. This specifically related the variables well for the proper prediction of salinity using the EC. More so, the p-values here indicate the conforming test results after experimentation. This implies that the model in Equation (5) ably describes the salinity and can be used for various predictions relating to the conditions at Doho.

\section{Analysis of Variance}

Table 3: Analysis of Variance

\begin{tabular}{llllll}
\hline Source & DF & Adj SS & Adj MS & F-Value & P-Value \\
\hline Regression & 4 & 13841 & 3460.2 & 0.13 & 0.970 \\
$\mathrm{pH}$ & 1 & 2243 & 2242.8 & 0.08 & 0.774 \\
$\mathrm{~K}$ & 1 & 5788 & 5788.3 & 0.22 & 0.646 \\
$\mathrm{Na}$ & 1 & 8963 & 8963.0 & 0.34 & 0.568 \\
$\mathrm{Ca}$ & 1 & 205 & 204.9 & 0.01 & 0.931 \\
Error & 20 & 530947 & 26547.3 & & \\
Total & 24 & 544788 & & & \\
\hline
\end{tabular}

\section{Model Equation}

$E C=281-26.0 p H+103 K+18.3 \mathrm{Na}+$ $5.5 \mathrm{Ca}$

Equation (5) also signifies that given the basic parameters like potassium, $\mathrm{pH}, \mathrm{Calcium}$ and
Sodium, in the right ratios, we can have an approximate but reliable value of the EC so as to determine the salinity. We can also mathematically predict the future salinity levels and ably use the model to predict the same elsewhere.

Figure 7: Residual Plot for EC

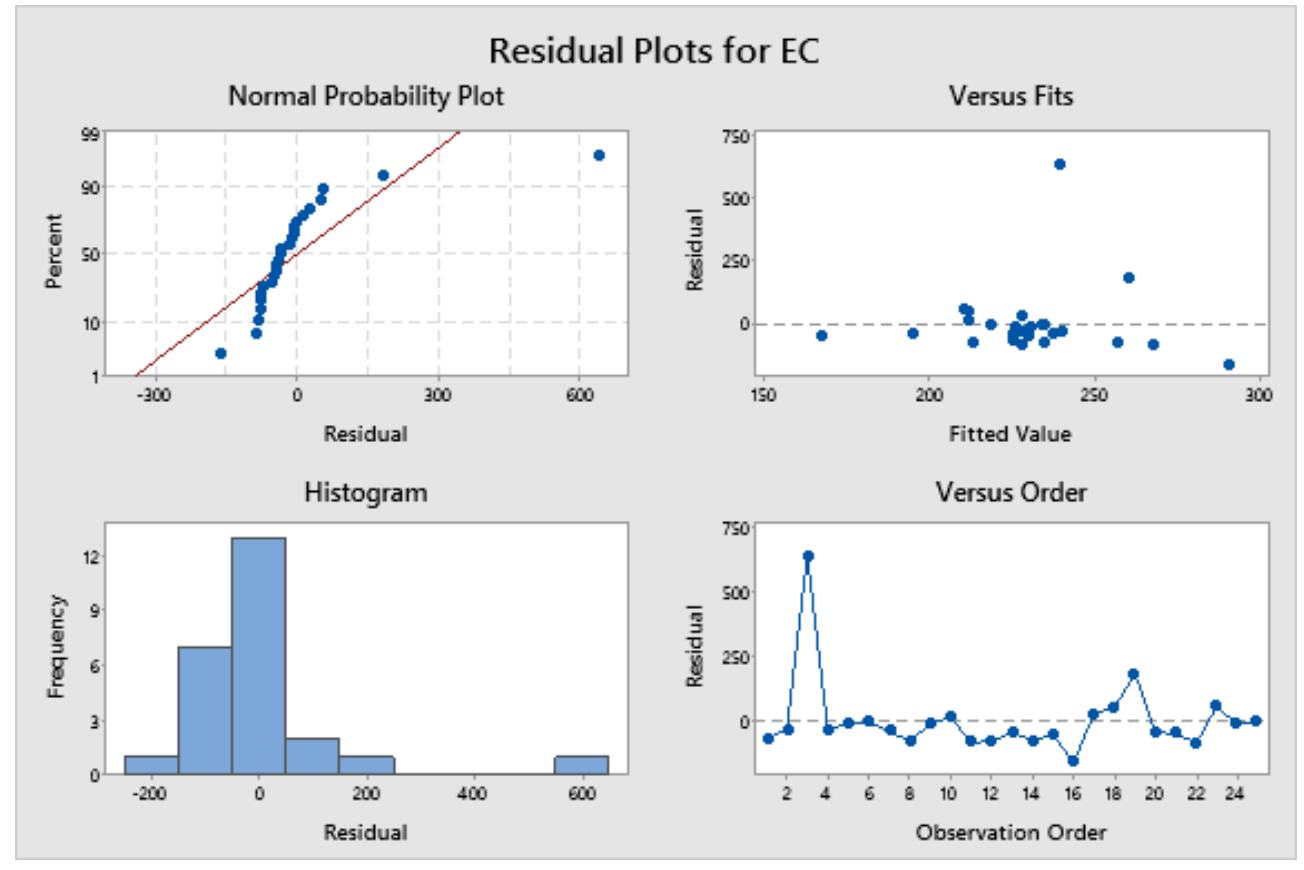

45 | This work is licensed under a Creative Commons Attribution 4.0 International License. 
The residuals in Figure 7 follow a normal distribution which means that our model fits the values for the predicted and actual values. From the above figure, it is acceptable for some values to fall below the line of prediction and others to fall under. In this design, there is a value that is extreme which is an outlier and would require further investigation.

\section{CONCLUSION}

This model can be used to determine how much chemical component should be exposed to the irrigation water so that it remains safe for rice growing. The model is able to approximate the salinity levels of the water which is a good tool for policymakers and scheme managers to regulate the amounts of chemical exposure in the water to focus on bigger rice yields.

There is a need for routine data collection on the quantities of salinity in the soil and rice yields such that production can be predicted at different salinity levels. This would be good since it can inform the decision on how much should be applied to realize high rice yields.

\section{ACKNOWLEDGEMENT}

We acknowledge the contribution and support of the management of Doho Irrigation Scheme Management and Busitema University, where we are employed.

\section{REFERENCES}

Ajala, O. N., Olaniyan, J. O., Ajala et al., H. E., \& Affinnih, K. (2015). The assessment of water quality for irrigation and sediment along Asa River. Agrosearch, 15(2), 21-30.

Al-Mukhtar, M., \& Al-Yaseen, F. (2019). Modeling water quality parameters using data-driven models, a case study Abu-Ziriq marsh in south of Iraq. Hydrology, 6(1), 24.

Bai, R., Chen, L., Zhang, X., Wei, G., \& Wei, C. (2017). Effect of salinity and soil temperature on the growth and physiology of drip-irrigated rice seedlings. Archives of Agronomy and Soil Science, 63(4), 513-524.

Bauder, T. A., Waskom, R. M., Davis, J. G., \& Sutherland, P. L. (2011). Irrigation Water Quality Criteria. Colorado State Univesity Extension.

Bendra, B., Fetouani, S., Laffray, X., Vanclooster, M., Sbaa, M., \& Aleya, L. (2012). Effects of irrigaton on soil physico-chemistry: A case study of the Triffa Plain. Irrigation and Drainage, 61, 507-519.

Bonansea, M., Rodriguez, M. C., Pinotti, L., \& Ferrero, S. (2015). Using multi-temporal Landsat imagery and linear mixed models for assessing water quality parameters in Río Tercero reservoir (Argentina). Remote Sensing of Environment, 158, 28-41.

Bwambale, E., Home, P. G., Raude, J. M., \& Wanyama, J. (2020). Development of a Water Allocation Model for Equitable Water Distribution at Doho Rice Irrigation Scheme, Uganda. Hydrology, 7(4), 62.

Chemura, A., Kutywayo, D., Chagwesha, T. M., \& Chidoko, P. (2014). An Assessment of Irrigation Water Quality and Selected Soil Parameters at Mutema Irrigation Scheme, Zimbabwe. Journal of Water Resource and Protection, 6, 132-140.

Cocozza, C., Pulvento, C., Lavini, A., Riccardi, M., Tognetti, R., \& D'Andria R. (2013). Effects of Increasing Salinity Stress and Decreasing Water Availability on Ecophysiological Traits of Quinoa (Chenopodium quinoa Willd.) Grown in a Mediterranean-Type Agroecosystem. Journal of Agronomy and Crop Science, 1999(4), 229240.

Dobermann, A \& Fairhurst T. (2000). Rice: Nutrient disorders \& nutrient management. Handbook series. Potash \& Phosphate Institute (PPI),

46 This work is licensed under a Creative Commons Attribution 4.0 International License. 
Potash \& Phosphate Institute of Canada (PPIC) and International Rice Research Institute. 191.

Rahman, A. L., Islam, M., Hossain, M. Z., \& Ahsan, M. A. (2012). Study of the seasonal variations in Turag river water quality parameters. African Journal of Pure and Applied Chemistry, 6(10), 144-148.

Salman, M., Peck, E., Fereres Castiel, E., \& García Vila, M. (2020). Policy guide to improve water productivity in small-scale agriculture: The case of Burkina Faso, Morocco and Uganda. Rome, FAO.

Uhegbu, F. O., Iweala, E. E., \& Kanu, I. (2011). Studies on the chemical and antinutritional content of some Nigerian spices. International Journal of Nutrition and Metabolism, 3(6), 7276.

World Soil Resources Reports (WSRS). (2007) Advances in the Assessment and Monitoring of Salinization and Status of Biosaline Agriculture. Reports of expert consultation held in Dubai, United Arab Emirates, 26-29 November 2007. World Soil Resources Reports No. 104. FAO, Rome. 